\title{
ASSESSING THE PERFORMANCE IMPACTS OF INFORMATION \\ SYSTEMS FROM THE RESOURCE-BASED PERSPECTIVE: AN EMPIRICAL TEST OF THE INDIRECT EFFECT OF IS
}

\author{
Michael J. Zhang \\ Sacred Heart University \\ Fairfield, Connecticut
}

\begin{abstract}
Research into the strategic impacts of information systems (IS) from the resource-based view of competitive advantage has increasingly embraced the indirect effect of IS on firm performance; that is, IS interact with other complementary organizational resources in infuencing firm performance. Using both survey and archival data, this study set out to test the indirect effect of IS and determine the complementary organizational resources contributing to IS impacts on firm performance. The results provide additional evidence in support of the indirect performance effect of IS. Specifically, the study found that the performance impacts of IS arose from their interactions with firm-specific knowledge, information, vertical integration and related diversification that complemented IS.
\end{abstract}

\section{Introduction}

Over the past decade, the resource-based view of competitive advantage has emerged as a popular approach to examining the strategic roles of information systems (IS) (Mata et al., 1995; Powell \& Dent-Micaleff, 1997; Lado \& Zhang, 1998; Bharadwaj, 2000; Byrd, 2001; Kearns \& Lederer, 2003; Wade \& Hulland, 2004; Zhang, 2005). One critical issue in the resource-based inquiry of the strategic impacts of IS is whether IS alone can lead to competitive advantage or they must work in conjunction with other organizational resources in order to provide strategic benefits (Wade \& Hulland, 2004). The former suggests a direct effect of IS on firm performance, whereas the latter implies an indirect effect of IS. While researchers have increasingly embraced the latter by arguing that IS complemented by certain organizational resources may lead to competitive advantage and superior performance (Feeny \& Ives, 1990; Clemons \& Row, 1991; Powell \& Dent-Micaleff, 1997; Lado \& Zhang, 1998; Bharadwaj, 2000), there has been relatively less empirical attention to testing the indirect effect of IS. Since the indirect effect of IS has become more and more influential in current thinking of how to evaluate and manage IS resources (Powell \& Dent-Micaleff, 1997; Wade \& Hulland, 2004), more empirical evidence is needed to ascertain this effect.

Furthermore, even though the indirect effect of IS generally exists, we still don't know enough about what specific organizational resources complement IS 
in influencing a firm's competitive position or performance (Wade \& Hulland, 2004). While the normative literature proposes a number of potential organizational complements to IS (Feeny \& Ives, 1990; Clemons \& Row, 1991; Kettinger et al., 1994; Powell \& Dent-Micaleff, 1997), the performance impacts of many of those complementary resources have not been assessed in prior empirical research (Kettinger et al., 1994; Powell \& Dent-Micaleff, 1997). Discerning the influence of different IS complements on the IS-performance relationship would then increase our knowledge of what represents a relevant set of complementary resources that interact with IS in affecting firm performance (Wade \& Hulland, 2004).

The purpose of this study was twofold. First, it provided another assessment of the indirect effect of IS on firm performance. Second, by testing the relationships between three sets of firm-specific complements to IS and firm performance, the study sought to empirically determine what organizational resources complement IS in influencing firm performance. The remainder of the paper is organized as follows. The next section reviews the indirect effect of IS within the resourcebased research on IS impacts, as well as the existing empirical evidence. This is followed by an examination of the potential performance impacts of three types of organizational resources (unique organizational culture and structure, unique vertical integration and related diversification, and unique knowledge and information) that complement IS. The methodology section describes the empirical analysis, including the sample and data collection procedure, the measurement of the variables of interest, and the results. The discussion section presents the implications of the research findings, the limitations of the study, and some suggestions for future research and practice. The last section provides a summary and conclusions for the study.

\section{Literature Review and Hypotheses}

\section{The Resource-based View of Competitive Advantage}

As a popular theoretical perspective in the strategic management literature, the resource-based view of competitive advantage suggests that firms with unique and difficult to imitate or substitute resources and capabilities can gain sustainable competitive advantage and superior performance (Barney, 1991). Over the past decade, the resource-based research has placed increasing emphasis on bundling a firm's resources and capabilities in creating and maintaining competitive advantage (Eisenhardt \& Martin, 2000; Denrell et al., 2003; Lippman \& Rumelt, 2003). Lippman and Rumelt (2003), for example, have developed and used the notion of payments (costs to a resource) to show that superior organizational performance is achieved by finding the most valuable combination of a firm's resources and bargaining over the marginal contribution of combining the resources. Drawing upon the concept of resource complementarity (the presence of a resource enhances the strategic values of other resources it complements) (Teece, 1986), resource-based researchers further posit that firms exploiting the complementarity among their resources and capabilities can create complex re- 
source/capability networks as barriers to imitation, thus enhancing the potential of achieving durable competitive advantage (Collis \& Montgomery, 1998; Barney, 2002; Colbert, 2004). Recent empirical studies have shown that the combinative effects of complementary resources and capabilities influence the competitive performance of firms (Carmeli \& Tishler, 2004; Song et al., 2005). Song et al. (2005), for instance, found a synergistic effect between two complementary organizational capabilities (marketing-related and technology-related) on firm performance in the high turbulence environment.

\section{The Resource-based View of the Strategic Roles of IS}

Since the early 90 s, IS researchers have turned to the resource-based view in examining the strategic roles of IS and explaining the "productivity paradox" regarding the strategic impacts of IS (Feeny \& Ives, 1990; Clemons \& Row; 1991; Mata et al., 1995; Powell \& Dent-Micaleff, 1997; Lado \& Zhang, 1998; Bharadwaj, 2000; Byrd, 2001). The early resource-based analyses viewed IS as commodity-like resources that are generally neither unique nor difficult to imitate, hence rarely resulting in sustainable competitive advantage (Clemons, 1986; Clemons \& Row, 1991; Mata et al., 1995). In the literature, this perspective is known as the "strategic necessity hypothesis" (Clemons \& Row, 1991).

While acknowledging that the direct effect of IS rarely exists, more recent resource-based inquiry has shown that IS may still have an indirect effect on a firm's competitive position or performance. That is, despite lacking the characteristics required for sustainable competitive advantage, IS may exert positive influence on firm performance through their relationships with other organizational resources. Following the logic of resource complementarity (Teece, 1986), IS and strategy researchers have argued that firms whose IS are complemented by other firm-specific and hard-to-copy organizational resources are in a better position to defend their IS-derived competitive advantage than those that lack such resources (Feeny \& Ives, 1990; Clemons \& Row, 1991; Powell \& DentMicaleff, 1997; Bharadwaj, 2000; Tippins \& Sohi, 2003). According to this line of reasoning, though the necessary software and hardware used by a firm's IS can be easily imitated, it is more difficult for its competitors to copy the unique and intangible resources the firm uses in implementing and exploiting its IS. Moreover, blending IS with other organizational resources may create a complex set of complementary resources that are not easily matched by competitors, thus sustaining IS-based advantage (Bharadwaj, 2000).

Despite gaining acceptance among researchers who analyze the strategic impacts of IS from the resource-based perspective, the indirect effect of IS has not been subject to close empirical scrutiny. Since it was first proposed in the early $90 \mathrm{~s}$, the indirect effect of IS has been tested in only two studies. In a longitudinal study of thirty IS considered as 'classic' cases of strategic use of information technology in the literature, Kettinger et al. (1994) explored the potential influence of a number of organizational factors on the sustainability of the IS-based competitive advantage. They found an established technological base and sub- 
stantial capital availability as two main organizational resources that differentiated the IS producing sustained superior performance from the IS resulting in only temporary superior performance. These findings seem to provide initial evidence for the indirect effect of IS, although the effects of several resources (e.g., competitive scopes and information resources) that might potentially affect IS-derived advantage were not tested due to lack of data availability.

In a subsequent study, Powell and Dent-Micallef (1997) investigated the indirect effect of IS with cross-sectional data collected from 67 U.S. retailers. They examined and tested the relationships between three sets of organizational resources (information technology resources, complementary human resources, and complementary business resources) and perceived firm performance. The complementary human resources under study included open organization, open communications, organizational consensus, CEO commitment, organizational flexibility, and IT-strategy integration. The complementary business resources encompassed supplier relationships, IT training, business process design, team orientation, benchmarking, and IT planning. Powell and Dent-Micallef found that IT resources alone did not explain significant firm performance. They further found that some retailers gained performance advantages from using complementary human resources. Since the empirical testing of the study focused on bundles of complementary resources, the performance effects of individual complementary resources were not closely checked. Moreover, it remains unclear whether the complementary human resources under study were unique to the firms.

While generally supporting the indirect effect of IS, the empirical works by Kettinger et al. (1994) and Powell and Dent-Micallef (1997) were insufficient in identifying a relevant set of complementary organizational resources contributing to the indirect effect of IS. The following sections examine three types of distinctive organizational resources (unique organizational culture and structure, unique vertical integration and related diversification, and unique knowledge and information) and their interactions with IS in affecting firm performance. These complementary resources were selected as the foci of this study because they not only may contribute to IS-based competitive advantage, but also tend to be firm-specific and hard to copy. As noted above, a firm is in a better position to protect its IS-based advantage if its IS are complemented by other organizational resources that are idiosyncratic to the firm and difficult to imitate (Clemons \& Row, 1991; Bharadwaj, 2000).

\section{Unique Organizational Culture and Structure That Complement IS}

Organization and strategy researchers have long recognized the key roles of organizational culture and structure in developing and leveraging resources and capabilities for competitive advantage (Amit \& Schoemaker, 1993; Miller \& Whitney, 1999; Galbraith, 2001; Barney, 2002; Miller, 2003). Barney (2002) argues that, without supportive organizational culture and structure, a firm is less likely to exploit the full competitive potential of its resources and capabilities. Miller (2003) showed how Citicorp, under the leadership of John Reed, used 
different cultural and structure mechanisms (e.g., a collaborative culture, project teams and cross-functional committees) to turn its international branch network into a source of sustainable competitive advantage. Besides complementing other organizational resources and capabilities, organizational culture and structure tend to be imperfectly imitable. It is well recognized in the resource-based literature that idiosyncratic and valuable organizational cultures are difficult to duplicate because they represent socially complex phenomena (Barney, 1986b; 1991; Fiol, 1991; Lado \& Wilson, 1994). As Barney (1991) notes, even though firms lacking certain attributes of a valuable organizational culture may understand how these attributes contribute to competitive performance, systematic efforts to create those attributes typically require simultaneous manipulation of complex social relationships, hence making imitation costly. Research into the organizational impacts of organizational structure has also shown that duplicating effective organizational structures is difficult in that they are often context-bound (i.e., they must be properly matched with the particular organizational situations) and require synergistic integration of different organizational elements (e.g., processes, systems and capabilities) (Miller \& Whitney, 1999; Galbraith, 1995; 2000; 2001). To illustrate the complexity involved in designing and adopting an organizational structure, Galbraith (2000: 173) makes the following observation regarding the difficulty multinational firms may face in designing a transnational structure:

"It is not simply a matter of distributing regional and global mandates. Rather it involves the creation of global management teams for the top group, as well as other key groups like product-development teams; the design of global business processes and information systems; the creation of new measurement and reward systems; and, finally, the use of managers with a global mind-set and team skills."

It is evident from several streams of research that a firm's organizational culture and structure are instrumental in influencing its ability to derive strategic benefits from IS. The absence of organizational culture and structure supporting the smooth implementation and use of IS has been documented as a major cause of many system failures in the IS implementation and adoption literature. Several empirical studies, for instance, have found relatively low system use among firms lacking a culture and reward systems that support IS adoption (Zuboff, 1988; Constant et al., 1996; Goodman \& Darr, 1998). The business process reengineering research also demonstrates that firms whose structures and processes are not aligned with their new IS have experienced difficulty in reaping the benefits of the IS (Hammer \& Champy, 1993; Keen, 1993; Boar, 1994). Moreover, recent research on organizational barriers to knowledge management suggests that firms may not be able to turn data and information into useful knowledge and organizational results from their IS without a supportive organizational culture and structure (Davenport et al., 2001). Even if new knowledge is created from employing IS, sharing the new knowledge may be limited by cultural and structural constrictions (Zuboff, 
1988; Ciborrra \& Patriota, 1998). Aside from affecting the economic impacts of IS, firm-specific organizational culture and structure make it difficult for competitors to imitate the IS they complement because organizational culture and structure tend to be socially complex and hence difficult to imitate, as noted above.

\section{Hypothesis 1: IS complemented by unique organizational culture and structure are positively related to firm performance.}

\section{Unique Vertical Integration and Related Diversification That Complement IS}

Strategy scholars have long argued that competitive advantage can be achieved with competitive scope (Porter, 1991; Christensen, 2001). Among several dimensions of competitive scope are vertical integration and related diversification. The former describes the extent of a firm's integration into the businesses of its buyers or suppliers, while the latter refers to the range of related businesses the firm competes in (Porter, 1985). Both vertical integration and related diversification have been shown as potential sources of sustainable competitive advantage in the strategic management literature. Research based on transaction cost economics, resourcebased theory and knowledge-based view of the firm suggest that vertical integration may confer economic value by allowing the firm to avoid market exchange costs arising from opportunism, uncertainty and asset specificity (Williamson, 1985) and better manage and utilize its unique and hard-to-copy skills and knowledge in certain functions (Conner \& Prahalad, 1996; Barney, 2002). Moreover, Barney (2002) has recently examined the roles of governance skills in vertical integration and argued that firms with superior governance skills (e.g., ability to analyze uncertain and complex economic transactions) that are rare and costly to imitate may increase and sustain competitive advantage derived from vertical integration.

The related diversification literature indicates that related diversification based on sharing related activities or competencies is generally associated with superior firm performance (Markides \& Williamson, 1994; Palich et al., 2000; Tanriverdi \& Venkatraman, 2005). Further, certain types of related diversification tend to be more firm-specific and harder to duplicate. In his analysis of the potential linkage between related diversification and sustainable competitive advantage, Barney (2002) notes that related diversification that exploits rare and costly to imitate economies of scope (e.g., core competencies) is more unique and immune from direct imitation than one based on common and less costly to imitate economies of scope (e.g., shared activities and risk reduction).

IS researchers adopting the resource-based perspective note that firms can create and maintain competitive advantage from merging IS with unique related diversification or vertical integration (Feeny \& Ives, 1990; Clemons \& Row, 1991; Kettinger et al., 1994). Clemons and Row (1991) identify three ways IS can be deployed to exploit a firm's unique diversification scope for competitive advantage. First, firms with wider ranges of related businesses may achieve a scale advantage from using IS to improve coordination of similar activities and resources across various markets, putting their rivals with more limited business scopes at 
a cost disadvantage. Second, by facilitating the transfer and sharing of critical skills and knowledge among multiple businesses, IS give a firm with a broader industry scope better leverage of its expertise and hence competitive advantage. Third, IS may be used to generate synergistic effects (i.e., creating more value for the customer from combining different, but complementary resources in different lines of business).

Firms may also exploit variations in vertical integration to derive more performance benefits from IS. A firm performing more vertically related activities can design and deploy IS to leverage unique information and knowledge resources from its upstream or downstream businesses, hence creating an advantageous position over its less vertically integrated competitors (Feeny \& Ives, 1990). In a classic case, Otis (once an independent company of elevator manufacturing and service) installed a remote diagnostic computer system in the elevators it produced to capture and provide critical information to its service database. Such unique information created by the system enabled Otis to obtain competitive advantage over other elevator service providers (Neumann, 1994).

On the other hand, firms with shorter value chains may use IS to form a network of "quasi-vertical" or "virtual" integration with their trading partners (Clemons \& Row, 1991; Lei et al., 1996). IS-based virtual integration allows individual firms within the network to enjoy operational benefits of vertical integration (e.g., higher efficiency and increased coordination), while also reducing the transaction costs and risks associated with vertical integration and realizing the production economies available to separate, specialized firms (Konsynski \& McFarlan, 1990; Clemons \& Row, 1991). Although competitors with full vertical integration may potentially match the level of operational integration, it is not as easy for them to match the production economies and flexibility of independent and specialized firms that are connected together by IS (Clemons \& Row, 1991).

\section{Hypothesis 2: IS complemented by unique vertical integration and related} diversification are positively related to firm performance.

\section{Unique Knowledge and Information That Complement IS}

It is widely recognized today that knowledge and information represent the most important resources of competitive advantage (Itami 1987; Nonaka \& Takeuchi, 1995; Quinn et al., 1996; Spender \& Grant, 1996). Knowledge and information not only increasingly add value to products and services (Davis \& Botkin, 1994), but also play a vital role in transforming resources and capabilities into dynamic core competencies (Prahalad \& Hamel, 1990; Leonard-Barton, 1995; Grant, 1996). Moreover, because organizational knowledge tends to be tacit, socially complex, embedded in firm-specific routines and processes, and nontradeable in strategic factor markets, the knowledge-based advantage is difficult to copy and thus sustainable (Polanyi, 1967; Barney, 1986a; Reed \& DeFillippi, 1990; Nonaka, 1994). Like knowledge, firm-specific information can be hard to imitate (Itami, 1987). For instance, proprietary databases (e.g., customer databases) may 
take years to build, and their development and access are often specific to a firm's interactions with its business environments (Feeny \& Ives 1990; King \& Grover, 1991, Siguaw \& Enz, 1999; Winter, 2001).

It is evident in the literature that the successful implementation and exploitation of IS to achieve such operational benefits as production efficiency, product flexibility and close cross-functional coordination depend upon a firm's knowledge resources (Kotha, 1995; Upton, 1995; Lei et al., 1996; Hitt et al., 1998). Research on advanced manufacturing technologies (AMT) such as computer-aided design (CAD) and computer aided manufacturing (CAM) demonstrates that the richness of a firm's tacit knowledge (the insights, heuristics and experience of the firm's employees) applied in the procedures and workflows supported by AMT influences the long-term implementation success of AMT (Lei et al., 1996). For example, Upton (1995) argues that manufacturers with workers adept at carrying out quick changeovers and responding to the demands of new customers are more likely to create a manufacturing system that combines IT and employee skills to make IS-based flexibility work. Parthasarthy and Sethi (1992) posit that firms whose employees possess the skills for selecting, processing and transmitting complex information quickly would enjoy greater economic gains from IS-based flexibility. Kotha's (1995) case study of how National Bicycle Industrial Company (NBIC), a Japanese bicycle manufacturer, developed and implemented mass customization for competitive advantage revealed that access to highly trained workers and substantial in-house expertise in engineering and manufacturing played a critical role in NBIC's ability to develop and deploy IS to offer a great variety of bicycles at low costs. The study also showed that the same knowledge resources enabled NBIC to use IS to integrate different functional activities and establish a close information network with its customers and suppliers.

The competitive advantage derived from combining human expertise with IS is harder to duplicate because employee skills and knowledge that complement IS are often unique and contingent on firm-specific organizational routines developed over an extended period of time. In their resource-based analysis of several IT-related resources, Mata et al. (1995) concluded that managerial skills in building, implementing and managing IT are rare among firms, require long periods of practice and learning, and involve complex social relations. The mass customization experience of NBIC mentioned above showed that the main rivals of NBIC had a hard time trying to imitate its approach to mass customization because NBIC's IS that supported its mass customization operation was built with in-house engineering and manufacturing expertise accumulated over many years (Kotha, 1995). Furthermore, firms blending their IS with unique knowledge resources may be able to create a complex set of complementary resources that are not easily matched by competitors (Lado \& Zhang, 1998; Bharadwaj, 2000).

A firm is also in a better position to derive IS-based advantage if the firm possesses unique information resources (Feeny $\&$ Ives, 1990). The presence of a proprietary database may create more strategic opportunities the firm can exploit with its IS (Sabherwal \& King, 1991; Kogut \& Zander, 1992). For instance, Kraft 
General Foods developed a repertoire of usable promotion programs, products, value-added ideas, and selling tools from employing a centralized IS to access and analyze sales and consumer data collected from 30,000 food stores nationwide (Treacy \& Wiersema, 1993). In a more recent example, Boston's Fairmont Copley Plaza Hotel provides its concierges with a guest-history database and street information through a computerized system to expedite guest service at the concierge desk. This IS support has consistently boosted the concierge's guest-satisfaction index close to $90 \%$ and promoted loyalty among the hotel's core group of guests (Siguaw \& Enz, 1999). Further, the possession of firmspecific information not only increases the value of IS, but also makes imitation difficult (Itami, 1987; Feeny \& Ives, 1990). While competitors may build similar IS easily, it is harder for them to develop the comparable database that may take a long time to build.

Hypothesis 3: IS complemented by unique knowledge and information are positively related to firm performance.

\section{Methodology}

\section{Sample and Data Collection}

The data for this study came from two sources. The data tapping the independent variables were gathered via a mail survey administered in 1998, and the data about the performance and control variables were obtained from the Research Insight (formerly known as Compustat) database. The target respondents of the survey were senior IS executives in large (Fortune and Forbes) firms in the U.S. Most of the respondents held the positions of either vice presidents of IS or chief information officers. The senior IS executive was chosen as the single informant in this study because of his or her familiarity with both IS and strategic management issues. Several previous studies have found increasing involvement of senior IS executives in strategic planning and control activities of firms (Applegate \& Elam, 1992; Earl \& Feeny, 1994). Furthermore, a recent study found the information offered by key IS executives consistent with the insights obtained from other senior members of management (Palmer \& Markus, 2000 ). Hence, IS researchers have increasingly relied on senior IS executives as single informants in gathering data about strategic IS issues (Karimi et al., 1996; Palmer \& Markus, 2000).

The contact information of the senior IS executives was obtained from the Directory of Top Computer Executives compiled by Applied Computer Research Inc. From this source, a sample of 879 firms that had financial data in the Research Insight database was identified. Before being mailed to the target respondents, the survey instrument was pre-tested and refined for content validity and item clarity with senior IS executives from five Fortune 500 companies headquartered in a midwestern state. One hundred and one questionnaires were undelivered or returned because the IS executives were no longer with the companies. Twenty-nine firms 
declined to participate in the study in writing, on the phone, or through e-mail. To boost the response rate, two follow-up mailings and one reminder letter were initiated after the first mailing. Of the 778 firms that received the questionnaires, a total of 164 responses were received, out of which 16 responses were unusable. The effective response rate was thus $19 \%$ (148 responses). Such a response rate is comparable to those reported in similar studies using senior IS executives in large firms (Sethi \& King, 1994; Powell \& Dent-Micallef, 1997; Byrd \& Turner, 2001; Kearns \& Lederer, 2003).

To test for potential nonresponse bias, the respondent firms were compared to their non-respondent counterparts with respect to sales and number of employees. T-test results showed no significant differences between the two groups: sales $(t=-1.227, p>.22)$ and number of employees $(t=-1.308, p>.19)$. In keeping with Armstrong and Overton (1977), another nonresponse bias check was conducted by comparing early with late respondents. T-tests of the mean differences for the three explanatory variables failed to reveal any significant differences: unique organizational culture and structure that complement IS $(\mathrm{t}=1.042$, $p>.304)$, unique vertical integration and related diversification that complement IS $(\mathrm{t}=1.226, \mathrm{p}>.228)$, and unique knowledge and information that complement IS $(t=-.875, p>.388)$. Together, these checks provided some evidence for the absence of non-response bias in the data set.

\section{Measures}

Independent variables. Based on the works by Feeny and Ives (1990), Clemons and Row (1991), and Kettinger et al. (1994), six items were developed to measure the six different unique organizational resources that complement IS. For each of the six items, the respondents were asked to indicate the extent to which the use and implementation of their IS required each of these resources on a five-point, Likert-type scale with anchors ranging from "Very great extent" $(=5)$ to "No extent" $(=1)$. To assess the construct validity and unidimensionality of the scale, a principal components factor analysis with varimax rotation was performed on the six items. The factor analysis (Table 1) revealed three factors explaining about $77.8 \%$ of the total variance and corresponding with the three proposed sets of complementary resources, respectively.

Dependent variables. Two popular measures of profitability, return on sales (ROS) and return on assets (ROA), were employed to measure the performance impacts of the unique organizational resources that complement IS. Both profitability ratios have been frequently used in previous assessments of the strategic impacts of IS (Kettinger et al., 1994; Brown et al., 1995; Tam, 1998; Li \& Ye, 1999). To smooth annual fluctuations and reduce short-term effects to some degree, a two-year (1998-1999) average was used for both variables.

Control variables. Since the firms participating in this study came from a variety of industries, it was necessary to control, to some degree, the different industry conditions under which the firms operated. To control for the industry effects, SIC codes were first used to classify the firms into four groups: 1) manufactur- 
Table 1

Factor Analysis of Unique Organizational Resources That Complement IS

\begin{tabular}{|c|c|c|c|}
\hline Item Description & $\begin{array}{l}\text { Unique Organizational } \\
\text { Culture \& Structure }\end{array}$ & $\begin{array}{l}\text { Unique Vertical Integration } \\
\text { \& Related Diversification }\end{array}$ & $\begin{array}{l}\text { Unique Knowledge } \\
\text { \& Information }\end{array}$ \\
\hline \multicolumn{4}{|c|}{$\begin{array}{l}\text { Please indicate the extent to which your information systems require each of the following complementary assets (resources which are used in } \\
\text { conjunction with the systems): }\end{array}$} \\
\hline 1. Proprietary databases & & & .860 \\
\hline 2. Firm-specific knowledge or skills & & & .805 \\
\hline $\begin{array}{l}\text { 3. Unique vertical integration between your company } \\
\text { and your suppliers, customers or distributors }\end{array}$ & & .797 & \\
\hline $\begin{array}{l}\text { 4. Unique range of related industries in which your } \\
\text { company competes }\end{array}$ & & .881 & \\
\hline 5. Unique organizational culture & .895 & & \\
\hline 6. Unique organizational structure & .914 & & \\
\hline Eigen Value & 2.40 & 1.31 & .96 \\
\hline$\%$ of common variance explained & 28.55 & 25.36 & 23.92 \\
\hline Cronbach Alpha & .83 & .68 & .57 \\
\hline
\end{tabular}


ing, 2) transportation and public utilities, 3) wholesale and retail trade, and 4) service. Where a firm operated in more than one industry, the firm's SIC code was determined by identifying the industry from which the firm received the largest percentage of sales and the corresponding SIC code. Three dummy variables (each with values of 0 or 1) were then created for the second (transportation and public utilities), the third (wholesale and retail trade) and the fourth (service) groups of firms. For each dummy variable, a firm was assigned a value of 1 if it belonged to a group.

The fourth control variable was firm size, which has frequently been used in previous studies involving firm performance as a dependent variable (Kivijarvi \& Saarinen, 1995; Tam, 1998; Li \& Ye, 1999). In keeping with Kettinger et al. (1994), firm size was measured with total assets. The fifth control variable was technological resources. A firm's technological resources may influence its ability to develop IS for sustainable competitive advantage (Kettinger et al., 1994). While a preferable measure of technological resources is $R \& D$ intensity, the Research Insight data for R\&D intensity were missing for many firms in the sample. An alternative measure (investment intensity operationalized as invested capital to sales), as recommended by Kettinger et al. (1994), was then used for technological resources. The last two control variables represent two types of financial slack: available slack and potential slack (Daniel et al., 2004). Reflecting a firm's ability to generate cash flow for reinvestment (Chakravarthy, 1986), financial slack needs to be controlled due to its influence on the firm's financial performance as well as its ability to invest in and develop IS (Kettinger et al., 1994; Daniel et al., 2004). Following convention (Bourgeois, 1981; Daniel et al., 2004), available slack was measured as the current ratio (current assets to current liabilities) and potential slack as the debt to equity ratio.

\section{Analyses}

To test the hypotheses, two sets of two-stage regression analyses were performed, using ROS and ROA as the dependent variables. In the first stage of each set of the analyses, the seven control variables were entered into the regression model as a set. In the second stage, the three independent variables were added to the equation. To avoid potential multicollinearity among the three independent variables, their factor scores were calculated from the factor analysis and used in the regression analyses.

\section{Results}

Table 2 reports the means, standard deviations and bi-variate correlations for all the variables. Unique knowledge and information that complemented IS were positively correlated with $\operatorname{ROS}(r=.17, p<.05)$, while unique vertical integration and related diversification that complemented IS were positively associated with ROA $(r=.20, p<.05)$. Unique organizational culture and structure that complemented IS were not significantly correlated with either ROS or ROA. Table 3 displays the results of the hierarchical regression analyses. Hypothesis 1 
Table 2

Means, Standard Deviations and Correlation Coefficients ${ }^{\mathrm{a}}$

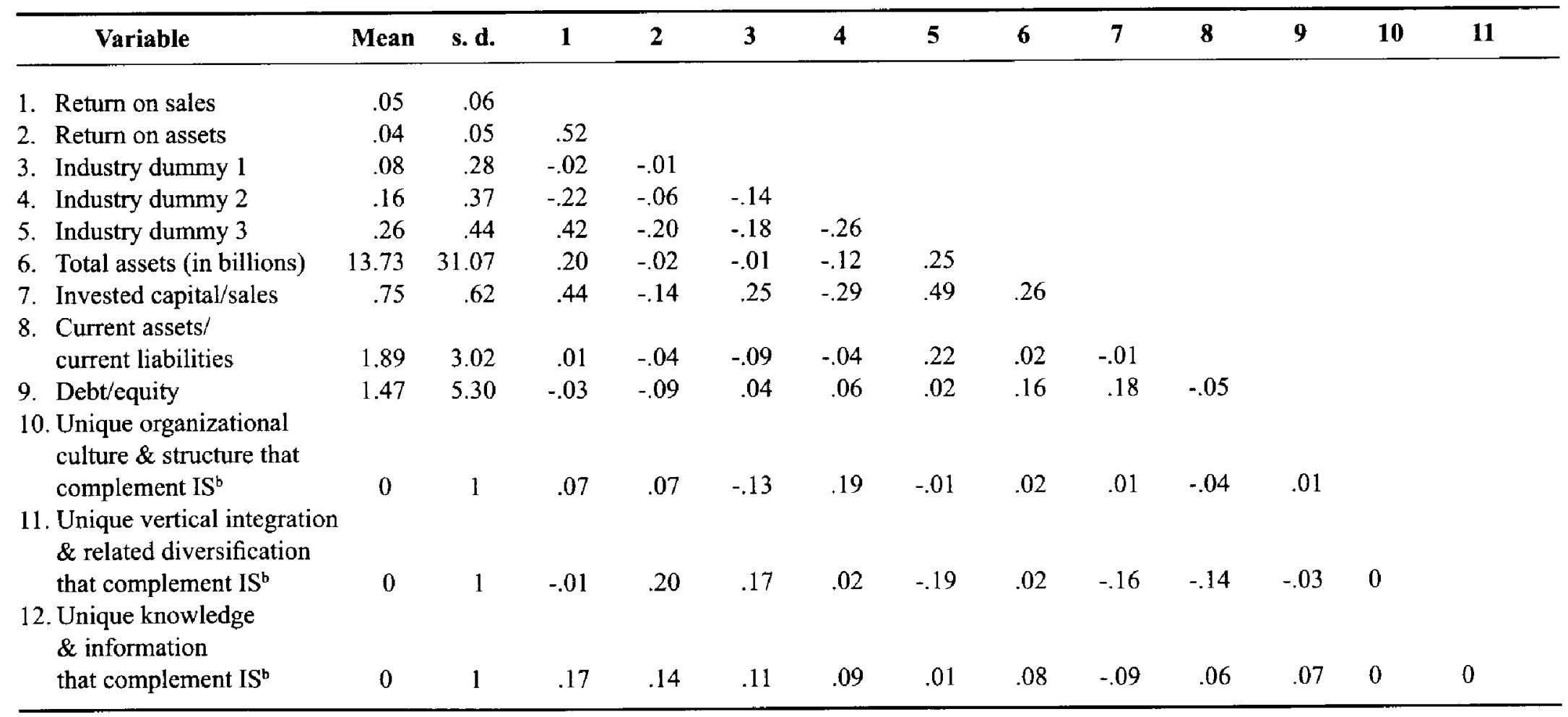

${ }^{a} \mathrm{~N}=148$. Correlations greater than or equal to .14 are significant at the .10 level; $r \geq .16$ are significant at the .05 level; $r \geq .21$ are significant at the .01 level; $r \geq .26$ are significant at the .001 level; all two-tail tests.

${ }^{b}$ The statistics of these variables are based on their factor scores. 
Table 3

Regression Results ${ }^{\mathrm{a}}$

\begin{tabular}{|c|c|c|c|c|}
\hline \multirow[b]{2}{*}{ Variables } & \multicolumn{2}{|c|}{ ROA } & \multicolumn{2}{|c|}{ ROS } \\
\hline & Model 1 & Model 2 & Model 3 & Model 4 \\
\hline Industry dummy 1 & -.05 & -.12 & -.07 & -.13 \\
\hline Industry dummy 2 & -.13 & $-.17^{+}$ & -.06 & -.09 \\
\hline Industry dummy 3 & $-.23 *$ & $-.25 *$ & $.22 *$ & $.19 *$ \\
\hline Firm size (total assets) & .04 & .01 & .08 & .04 \\
\hline $\begin{array}{l}\text { Investment intensity } \\
\quad \text { (invested capital/sales) }\end{array}$ & -.05 & .02 & $.34 * * *$ & $.39 * * *$ \\
\hline $\begin{array}{l}\text { Current ratio } \\
\text { (current assets/current liabilities) }\end{array}$ & .01 & .02 & -.05 & -.05 \\
\hline Debt/equity & -.07 & -.08 & -.10 & -.11 \\
\hline $\begin{array}{l}\text { Unique organizational culture } \\
\text { \& structure that complement IS }\end{array}$ & & .10 & & .06 \\
\hline $\begin{array}{l}\text { Unique vertical integration and relate } \\
\text { diversification that complement IS }\end{array}$ & & $.18^{*}$ & & .10 \\
\hline $\begin{array}{l}\text { Unique knowledge \& information } \\
\text { that complement IS }\end{array}$ & & $.19^{*}$ & & $.21 * *$ \\
\hline $\mathbf{R}^{2}$ & .06 & .13 & .27 & .33 \\
\hline$\Delta \mathrm{R}^{2}$ & & .07 & & .06 \\
\hline $\mathrm{F}$ & 1.43 & $2.10^{*}$ & $7.51 * * *$ & $6.60^{* * *}$ \\
\hline$\Delta F$ & & $3.49 *$ & & $3.54 *$ \\
\hline
\end{tabular}

${ }^{a} \mathrm{~N}=148$. Standardized regression coefficients are shown.

${ }^{+} \mathrm{p}<.10,{ }^{*} \mathrm{p}<.05,{ }^{* *} \mathrm{p}<.01,{ }^{* * *} \mathrm{p}<.001$

predicts that IS complemented by unique organizational culture and structure are positively related to firm performance. Models 2 and 4 show that unique organizational culture and structure that complemented IS were not significantly associated with either ROA or ROS. Therefore, Hypothesis 1 was not supported. Hypothesis 2 states that IS complemented by unique vertical integration and related diversification are positively related to firm performance. The same models reveal that unique vertical integration and related diversification that complemented IS were positively related to $\operatorname{ROA}(b=.18, p<.05)$, but not ROS. Hypothesis 2 was thus partially supported. Hypothesis 3 suggests that IS complemented by unique knowledge and information are positively related to firm performance. As shown in Models 2 and 4, unique knowledge and information that complemented IS were positively associated with both $\operatorname{ROS}(b=.21, p<.01)$ and $\operatorname{ROA}(b=.19$, $p<.05$ ), hence supporting Hypothesis 3 . 


\section{Discussion}

\section{Overview and Research Implications of the Findings}

This research sought to empirically test the indirect effect of IS on firm performance and identify several firm-specific, complementary organizational resources contributing to that effect. The results indicate that firms whose IS were complemented by unique knowledge and information enjoyed gains in ROS and ROA. IS complemented by unique vertical integration and related diversification could also lead to higher ROA. Consistent with the normative literature (Feeny \& Ives, 1990; Clemons \& Row, 1991) and the empirical work by Kettinger et al. (1994) and Powell and Dent-Micaleff (1997), these findings provide additional evidence in support of the resource-based argument that IS influence on firm performance arises from their interactions with other firm-specific and hard-to-copy organizational resources. While confirming the indirect effect of IS, this study differed from the previous studies by finding empirical support for the roles of unique knowledge, information, vertical integration and related diversification that complemented IS in affecting the relationship between IS and firm performance. One possible fruitful extension to the research on the indirect effect of IS is to identify and examine other distinct organizational resources that could potentially enhance IS impacts on firm performance.

Another possible direction for future inquiry in this line of research is to investigate the interrelationship between IS and organizational knowledge/information. Since IS are capable of helping firms develop valuable and firm-specific organizational knowledge and information (Trybula, 1997; Lado \& Zhang, 1998) that in turn can be used to facilitate the implementation and utilization of IS, a firm can create a reciprocal relationship between these two types of organizational resources, which could then increase the complexity of the resource complementarity and hence make imitation more difficult.

Contrary to the expectations and the findings by Powell and Dent-Micaleff, (1997), the study found no evidence for the performance influence of firm-specific organizational culture and structure that complemented IS. This unexpected non-finding might be due to the coarse measures used in the study (see the limitations of the study below). Another possible explanation is that some unique organizational cultures and structures in the sample might not exhibit certain desirable characteristics such as open organization and open communications (Powell \& Dent-Micaleff, 1997). Consequently, even if those organizational cultures and structures were perceived as firm-specific and complementary to IS, their interactions with IS did not exert positive influence on firm performance. It then appears that more in-depth studies that draw from comprehensive analyses of organizational culture and structure (e.g., O'Reilly et al., 1991) are needed to identify specific aspects or types of organizational culture and structure, which are not only conducive to the implementation and exploitation of IS, but also unavailable to competition. 


\section{Managerial Implications}

The findings from this research have practical implications for the strategic management of IS. While firms these days are investing heavily in building and deploying IS to improve their competitive positions, the performance impacts of such IS investments depend on the presence of certain firm-specific resources that complement the IS. A firm is more likely to reap economic benefits (gains in profitability) from its IS investment if it possesses firm-specific knowledge, information, vertical integration and related diversification that facilitate IS implementation and exploitation. Hence, creating and utilizing unique knowledge and information that increase the effectiveness of IS investments are as important as making the IS investments. Moreover, aligning IS with a firm's unique vertical integration and related diversification may increase the performance contributions of the IS.

The results presented here can be interpreted to imply a larger role for IS in helping firms gain competitive advantage than that suggested by those who question the strategic value of IS (Mata et al., 1995; Martinsons \& Martinsons, 2002). Contrary to the growing skepticism towards whether IS can be more than a "strategic necessity," the findings suggest that IS can be a source of competitive advantage and superior economic performance if they are complemented by certain distinct organizational resources. Accordingly, the critical issue facing firms and their managers is not whether they should invest in IS, but how to manage the complementarity between IS and other organizational resources to maximize IS payoffs.

\section{Limitations of the Study}

The findings in this study need to be interpreted within its limitations. First, the study relied on perceptual data collected from single informants in measuring organizational resources that complemented IS. Data collected in such a manner might be influenced by the respondents' cognitive biases and distortions, although objective measures were used to reduce similar biases and inaccuracies in collecting the data for the performance and control variables and avoid potential common method variance. Another measurement limitation lies in the use of single-item scales to measure the IS complements. These general measures might be insufficient to fully capture the complexity in certain complementary resources (e.g., unique organizational culture, and unique organizational structure) and subject to different interpretations by different respondents. The coarseness of the measures might then have contributed to the non-finding for unique, complementary organizational culture and structure as well as the low reliability of unique, complementary knowledge and information. Therefore, future research on the performance impacts of complementary organizational resources of IS need to develop and use multi-item scales with higher validity and reliability to measure these resources.

While the study controlled for a number of industry and organizational factors, there might be other potential performance determinants whose effects were not 
taken into account due to the lack of data and the small sample size. The exclusion of those variables might have resulted in overestimating or underestimating the contributions of the unique, complementary organizational resources to the indirect effect of IS (Berry \& Feldman, 1985). Whenever possible, future studies need to include other environmental and organizational attributes related to firm performance in order to obtain more accurate assessments of how unique, complementary organizational resources interact with IS in affecting firm performance.

As another limitation, the response rate $(19 \%)$ for the survey used in this research was relatively low. While comparable to those of similar studies, this response rate may limit the generalizability of the study results. Obtaining a high response rate for sensitive information concerning the strategic use of IS continues to be a challenge for researchers.

\section{Summary and Conclusions}

This study tested the indirect effect of IS on firm performance, which has received increasing attention in the resource-based research on the strategic roles of IS. Among three potential types of complementary organizational resources contributing to the indirect effect of IS, the study found that unique knowledge and information complemented IS in improving profitability. Although to a lesser degree, the study also found the presence of unique, complementary vertical integration and related diversification positively associated with profitability. On the other hand, unique organizational culture and structure which have been often deemed as critical to IS effectiveness and contributions to firm performance were not found to have any significant effect. Together, the results from this study not only provide empirical evidence that the indirect effect of IS may exist, but also increase our knowledge of IS complements that are more likely to contribute to IS-based competitive advantage. While representing one of the few empirical endeavors to assess the indirect effect of IS and identify what types of complementary organizational resources contribute to that effect, this study suggests that additional research based on more rigorous methodology is needed to help us fully understand what represent a relevant set of IS complements that affect the IS-performance relationship.

\section{References}

Amit, R. P., \& Schoemaker, J. H. (1993). Strategic assets and organizational rent. Strategic Management Journal, 14, 33-46.

Applegate, L. M., \& Elam, J. J. (1992). New information systems leaders: A changing role in a changing world. MIS Quarterly, I6(4), 469-490.

Armstrong, J. S., \& Overton, T. (1977). Estimating nonresponse bias in mail surveys. Journal of Marketing Research, 14, 396-402. 
Barney, J. B. (2002). Gaining and sustaining competitive advantage. Upper Saddle River, NJ: Prentice Hall.

Barney, J. B. (1991). Firm resources and sustained competitive advantage. Journal of Management, $I 7(1), 99-120$.

Barney, J. B. (1986a). Strategic factor markets: Expectations, luck, and business strategy. Management Science, 86, 1231-1242.

Barney, J. B. (1986b). Organizational culture: Can it be a source of sustained competitive advantage? Academy of Management Review, 11, 656-665.

Berry, W., \& Feldman, S. (1985). Multiple regression in practice. Newbury Park, CA: Sage.

Bharadwaj, A. S. (2000). A resource-based perspective on information technology capability and firm performance: An empirical investigation. MIS Quarterly, 24(1), 169 196.

Boar, B. (1994). Information technology and business alignment: A strategic assessment. In B. Voss, \& D. Willey (Eds.), Handbook of business strategy. New York: Faulkner \& Gray.

Bourgeois, L. (1981). On measurement of organizational slack. Academy of Management Review, 6(1), 29-40.

Brown, R. M., Gatian, A. W., \& Hicks, J. O., Jr. (1995). Strategic information systems and financial performance. Journal of Management Information Systems, 11(4), 215-248.

Byrd, T.A. (2001). Information technology: Core competencies, and sustained competitive advantage. Information Resources Management Journal, 14(2), 27-36.

Byrd, T. A., \& Turner, D. E. (2001). An exploratory analysis of the value of the skills of IT Personnel: Their relationship to IS infrastructure and competitive advantage. Decision Science, 32(1), 21-54.

Carmeli, A., \& Tishler, A. (2004). The relationships between intangible organizational elements and organizational performance. Strategic Management Journal, 25, 1257-1278.

Chakravarthy, B. (1986). Measuring strategic performance. Strategic Management Journal, $7(5), 437-458$.

Christensen, C. M. (2001). The past and future of competitive advantage. Sloan Management Review, 42(2), 105-109.

Ciborra, C. U., \& Patriota, G. (1998). Groupware and teamwork in R\&D: Limits to learning and innovation. $R \& D$ Management, 28(1), 1-10. 
Clemons, E. K. (1986). Information systems for sustainable competitive advantage. Information \& Management, $11(3), 131-136$.

Clemons, E. K., \& Row, M. C. (1991). Sustaining IT advantage: The role of structural differences. MIS Quarterly, 15(3), 275-292.

Colbert, B. A. (2004). The complex resource-based view: Implications for theory and practice in strategic human resource management. Academy of Management Review, $29(3), 341-359$.

Collis, D. J., \& Montgomery, C. A. (1998). Corporate strategy: A resource-based view. Boston: Irwin/McGraw-Hill.

Conner, K., \& Prahalad, C. K. (1996). A resource-based theory of the firm: Knowledge versus opportunism. Organizational Science, 7, 477-492.

Constant, D., Sproull, L., \& Kiesler, S. (1996). The kindness of strangers: On the usefulness of weak ties for technical advice. Organization Science, 7(2), 119-135.

Daniel, F., Lohrke, F., Fornaciari, C., \& Turner, R. (2004). Organizational slack and firm performance: A meta-analysis. Journal of Business Research, 57, 565-574.

Davenport, T. H., Harris, J. G., De Long, D. W., \& Jacobson, A. L. (2001). Data to knowledge to results: Building an analytic capability. California Management Review, 43(2), 117-138.

Davis, S., \& Botkin, J. (1994). The coming of knowledge-based business. Harvard Business Review, 72(5), 165-170.

Denrell, J., Fang, C., \& Winter, S. G. (2003). The economics of strategic opportunity. Strategic Management Journal. 24, 977-990.

Earl, M. J., \& Feeny, D. F. (1994). Is your CIO adding value? Sloan Management Review, $35(3), 11-20$.

Eisenhardt, K., \& Martin, J. (2000). Dynamic capabilities: What are they? Strategic Management Journal, 21, 1105-1121.

Feeny, D. F., \& Ives, B. (1990). In search of sustainability: Reaping long-term advantage from investments in information technology. Journal of Management Information Systems, 7, 27-46.

Fiol, C. M. (1991). Managing culture as a competitive resource: An identity-based view of sustainable competitive advantage. Journal of Management, 17(1), 191-211.

Galbraith, J. (2001). Building organizations around the global customer. Ivey Business Journal, 66(1), 17-24. 
Galbraith, J. (2000). Designing the global corporation. San Francisco: Jossey-Bass.

Galbraith, J. (1995). Designing organizations: An executive briefing on strategy, structure, and process. San Francisco: Jossey-Bass.

Goodman, P. S., \& Darr, E. D. (1998). Computer-aided systems and communities: Mechanisms for organizational learning in distributed environments. MIS Quarterly, 22(4), 417-440.

Grant, R. M. (1996). Prospering in dynamically competitive environments: Organizational capability as knowledge integration. Organization Science, 7(4), 375-387.

Hammer, M., \& Champy, J. (1993). Reengineering the corporation: A manifesto for business revolution. New York: Harper Business.

Hitt, M. A., Keats, B. W., \& DeMarie, S. M. (1998). Navigating in the new competitive landscape: Building strategic flexibility and competitive advantage in the 21 st century. Academy of Management Executive, 12(4), 22-42.

Itami, H. 1987. Mobilizing invisible assets. Cambridge, MA: Harvard University Press.

Karimi, J., Gupta, Y. P., \& Somers, T. M. (1996). The congruence between a firm's competitive strategy and information technology leader's rank and role. Journal of Management Information Systems, 13(1), 63-88.

Kearns, G. S., \& Lederer A. L. (2003). A resource-based view of strategic IT alignment: How knowledge sharing creates competitive advantage. Decision Sciences, 34(1), $1-30$.

Keen, P. (1993). Information technology and the management difference: A fusion map. IBM Systems Journal. 32, 17-39.

Kettinger, W. J, Grover, V., Guha, S., \& Segars, A. H. (1994). Strategic information systems revisited: A study in sustainability and performance. MIS Quarterly, 18(1),31-58.

King, W. R., \& Grover, V. (1991). The strategic use of information resources: An exploratory study. IEEE Transactions on Engineering Management, 38(4), 293-305.

Kivijarvi, H., \& Saarinen, T. (1995). Investment in information systems and the financial performance of the firm. Information \& Management. 28, 143-163.

Kogut, B., \& Zander, U. (1992). Knowledge of the firm, combinative capabilities, and the replication of technology. Organization Science, 3(3), 383-397.

Konsynski, B. R., \& McFarlan F. W. (1990). Information partnerships - Shared data, shared scale. Harvard Business Review, 68(5), 114-120. 
Kotha, S. (1995). Mass customization: Implementing the emerging paradigm for competitive advantage. Strategic Management Journal, 16, 21-42.

Lado, A. A. \& Wilson, M. C. (1994). Human resource systems and sustained competitive advantage: A competency-based perspective. Academy of Management Review, 19(4), 699-727.

Lado, A. A., \& Zhang, M. J. (1998). Expert systems, knowledge development and utilization, and sustained competitive advantage: A resource-based model. Journal of Management, 24(4), 489-509.

Lei, D., Hitt, M. A., \& Goldhar, J. D. (1996). Advanced manufacturing technology: Organizational design and strategic flexibility. Organization Studies, 17(3), 501-517.

Leonard-Barton, D. (1995). Wellsprings of knowledge: Building and sustaining the sources of innovation. Boston: Harvard Business School Press.

Li, M., \& Ye, R. (1999). Information technology and firm performance: Linking with environmental, strategic and managerial contexts. Information \& Management, 35, 4351.

Lippman, S. A., \& Rumelt, R. P. (2003). The payments perspective: Micro-foundations of resource analysis. Strategic Management Journal, 24, 903-927.

Markides, C. C., \& Williamson, P. J. (1994). Related diversification, core competencies and corporate performance. Strategic Management Journal, 15, 149-165.

Martinsons, M. G., \& Martinsons, V. (2002). Rethinking the value of IT, again. Communications of the $A C M, 45(7), 25-26$.

Mata, F. J., Fuerst, W. L., \& Barney. J. B. (1995). Information technology and sustained competitive advantage: A resource-based analysis. MIS Quarterly, 19, 487-505.

Miller, D. (2003). An asymmetry-based view of advantage: Towards an attainable sustainability. Strategic Management Journal, 24(10), 961-976.

Miller, D., \& Whitney, J. O. (1999). Beyond strategy: Configuration as a pillar of competitive advantage. Business Horizons, 42(3), 5-14.

Neumann, S. (1994). Strategic information systems: Competition through information technologies. New York: Macmillan College Publishing Company.

Nonaka, I. (1994). A dynamic theory of organizational knowledge creation. Organization Science, 5(1), 14-37.

Nonaka, I., \& Takeuchi, H. (1995). The knowledge creating company. New York: Oxford University Press. 
O'Reilly, C., Chatman, J., \& Caldwell, D. (1991). People and organizational culture. Academy of Management Journal, 34, 487-516.

Palich, L. E., Cardinal, L. B., \& Miller, C. C. (2000). Curvilinearity in the diversificationperformance linkage: An examination of over three decades. Strategic Management Journal, 21(2), 155-174.

Palmer, J. W., \& Markus, M. L. (2000). The performance impacts of quick response and strategic alignment in specialty retailing. Management Science, 1I(3), 241-259.

Parthasarthy, R., \& Sethi, S. P. (1992). The impact of flexible automation on business strategy and organizational structure. Academy of Management Review, 17(1), 86-111.

Polanyi, M. (1967). The tacit dimension. Garden City, NY: Anchor.

Porter, M.E. (1991). Towards a dynamic theory of strategy. Strategic Management Journal, 12, 95-117.

Porter, M. E. (1985). Competitive advantage. New York: Free Press.

Powell, T. C., \& Dent-Micallef, A. (1997). Information technology as competitive advantage: The role of human, business, and technology resources. Strategic Management Journal, 18(5), 375-405.

Prahalad, C. K., \& Hamel, G. (1990). The core competence of the corporation. Harvard Business Review, 68(3), 79-91.

Quinn, J. B., Anderson, P., \& Finkelstein, S. (1996). Leveraging intellect. Academy of Management Executive, 10(3), 7-27.

Reed, R., \& DeFillippi, R. (1990). Causal ambiguity, barriers to imitation, and sustainable competitive advantage. Academy of Management Review, 15, 88-102.

Sabherwal, R., \& King, W. R. (1991). Towards a theory of strategic use of information resources. Information \& Management, 20, 191-212.

Sethi, V., \& King, W. R. (1994). Development of measures to assess the extent to which an information technology application provides competitive advantage. Management Science, 40(12), 1601-1627.

Siguaw, J. A., \& Enz C. A. (1999). Best practices in information technology. Cornell Hotel and Restaurant Administration Quarterly, 40(5), 58-71.

Song, M., Droge, C., \& Hanvanich, S. (2005). Marketing and technology resource complementarity: An analysis of their interaction effect in two environmental contexts. Strategic Management Journal, 26, 259-276. 
Spender, J. C., \& Grant, R. M. (1996). Knowledge and the firm: Overview. Strategic Management Journal, 17(Winter Special Issue), 5-9.

Tam, K. Y. (1998). The impact of information technology investments on firm performance and evaluation: Evidence from newly industrialized economies. Information Systems Research, $9(1), 85-98$.

Tanriverdi, H., \& Venkatraman, N. (2005). Knowledge relatedness and the performance of multinational firms. Strategic Management Journal. 26, 97-119.

Teece, D. J. (1986). Profiting from technological innovations: Implications for integration, collaboration, licensing, and public policy. Research Policy. 15, 285-305.

Tippins, M. J. \& Sohi, R. S. (2003). IT competency and firm performance: Is organizational learning a missing link? Strategic Management Journal, 24, 745-761.

Treacy, M., \& Wiersema, F. (1993). Customer intimacy and other value disciplines. Harvard Business Review, 71, 84-93.

Trybula, W. J. (1997). Data mining and knowledge discovery. Annual Review of Information Science and Technology, 32, 197-229.

Upton, D. M. (1995). What really makes factories flexible? Harvard Business Review, $82,74-84$.

Wade, M., \& Hulland, J. (2004). The resource-based view and information systems research: Review, extension, and suggestions for future research. MIS Quarterly, 28(1), 107-142.

Williamson, O. E. (1985). The economic institutions of capitalism. New York: Free Press.

Winter, R. S. (2001). A framework for customer service relationship management. California Management Review, 43(4), 89-105.

Zhang, M. J. (2005). Information systems, strategic flexibility and firm performance: An empirical investigation. Journal of Engineering \& Technology Management, 22, 163184.

Zuboff, S. (1988), In the age of the smart machine. New York: Basic Books.

Michael J. Zhang is an associate professor in the Department of Management at Sacred Heart University. He received his Doctor of Business Administration degree from Cleveland State University. His current research focuses on the strategic roles of information systems from the resource-based perspective of competitive advantage, including the performance impacts of IS support for organizational competencies, knowledge management, organizational learning, and 
organizational innovation. Dr. Zhang has published in Journal of Management, Journal of Managerial Issues, Journal of Engineering and Technology Management, International Journal of Knowledge Management, and Technovation. His email address is: zhangm@sacredheart.edu 